\title{
Suzanne R. Kunkel, J. Scott Brown and Frank J. Whittington. (2014). Global Aging: Comparative Perspectives on Aging and the Life Course. New York: Springer, 311 pp. ISBN: 9780826105462 (paperback)
}

\author{
Reviewed by Chris Gilleard*
}

Increasing attention is being paid to the rising numbers of older people in countries across the globe such that, we are told by the authors, more than 1.2 million people join the ranks of the older population per month. That's certainly a lot of birthdays. But what other meanings are we to attach to these kinds of statistics? The authors state that it is their intention to provide a text for those teaching courses in global aging and their students and that it is also their wish to focus on the growth and value of research going on outside North America and Europe. In short, they offer a kind of gerontological travelogue, drawing attention to the fact that aging is happening everywhere.

If travel broadens the mind, then a book such as this also has as its subtext the desire to broaden our understanding of aging by examining how aging and old age are viewed from non-European, non-North American perspectives. But like the traditional travelogue, the danger is that a little knowledge does no good; the few snippets of information from countries chosen seemingly at random for their cultural or geographic distance from European/North American academic centers fails to enlighten even as at

* Chris Gilleard, Division of Psychiatry, University College London, London, UK 
International Journal of Ageing and Later Life

times it entertains. At the same time, various cross-national methodologies are outlined (such as the models of long term care (LTC)), but none of these are developed beyond the chapters in which they appear. Perhaps this is an inevitable consequence of involving so many writers (18) in what is a relatively small book. Even so, this makes it a work to be dipped into rather than to be read systematically or be used as the framework for a more systematic course program.

At the same time, there are several interesting chapters and essays which are enlightening - including Scott Lynch's essay on income and mortality differentials and Applebaum, Robbins and Bardo's chapter outlining cross country models of national long-term care systems. There is also a useful attempt in Chapter 2 to categorize approaches toward studying global aging. The problem with the book is that while several such interesting and potentially enlightening perspectives on global aging are outlined, these are not followed through in structuring the book itself. Thus, it does not demonstrate to the reader how the study of global ageing might expand gerontology's or aging studies' models of aging and old age, beyond noting how different and yet how similar our human responses to aging are.

At the end of the book, the authors identify some of the key messages they would like their readers to take away with them. What follows are their summary points: (1) The world continues to be divided into developed and developing nations; (2) the gap between the haves and the have-nots is shrinking; (3) human health is improving and longevity is increasing; (4) national populations are aging; (5) public opinion toward older people is changing; (6) the family provides the core of life for most older people; (7) work and productivity are universal values; (8) retirement even in developing countries is becoming more common; (9) older adults are becoming more involved in community affairs; (10) most national governments are beginning to enact policies to support their senior population; (11) older people are actively driving much of the change; (12) a global aging science is emerging.

While one may not disagree with any of these points, none of them seem to have emerged as the necessary conclusions of what has gone before. In short, the book is full of such interesting starts with no systemizing route that follows them up. The authors end by calling for "global leaders." Where exactly global aging is leading remains unanswered. More path clearing is needed. 